\title{
Low-Dose Adrenocorticotropin Test in Patients with the Acquired Immunodeficiency Syndrome
}

Fernando H. Wolff, Claudio Nhuch, Luciana P. Cadore, Cristina L. Glitz, Francisco Lhullier and Tania W. Furlanetto
Division of Internal Medicine, Hospital de Clínicas de Porto Alegre, UFRGS, Porto Alegre, RS, Brazil

\begin{abstract}
Adrenocortical insufficiency is a serious complication of AIDS. Usually, integrity of the hypothalamo-pituitary-adrenal (HPA) axis in AIDS patients is assessed by measuring basal cortisol levels and cortisol response to $250 \mu \mathrm{g}$ of ACTH. Recent studies suggest that a lower ACTH dose increases the sensitivity of the procedure. In the present study, we investigated the prevalence of adrenal hypofunction in AIDS patients using a low-dose ACTH test $(1 \mu \mathrm{g})$, evaluated the clinical characteristics that might suggest this diagnosis, and the diseases and/or drugs that could be associated with it. We prospectively evaluated 63 very ill AIDS patients and 16 normal controls. A standard examination assessed the presence of signs and symptoms of adrenal insufficiency. Blood samples were collected before and 30 and 40 minutes after an injection of $1 \mu \mathrm{g} 1-24 \mathrm{ACTH}$. No opportunistic disease, signs, symptoms or drugs were associated with an abnormal cortisol response to ACTH. The lowest stimulated cortisol level in the control group was $18.5 \mu \mathrm{g} / \mathrm{dL}$; cortisol levels $\geq 18 \mu \mathrm{g} / \mathrm{dL}$ were taken to indicate a normal HPA axis. Test results revealed that 12/ 63 AIDS patients $(19 \%)$ had an abnormal HPA axis. With these data in mind, we suggest a prospective adrenal function evaluation of all severely ill AIDS patients.

Key Words: AIDS, adrenal insufficiency, ACTH, cortisol.
\end{abstract}

Patients infected with the human immunodeficiency virus (HIV) have complications secondary to the underlying immune defect - for example, mixed opportunistic infections and unusual neoplasms, such as Kaposi's sarcoma and high-grade lymphomas [1]. Endocrine dysfunction in the acquired immunodeficiency syndrome (AIDS) results primarily from involvement of the endocrine glands or central nervous system by infectious agents, from drug side effects, and from the wasting suffered by AIDS patients. Adrenocortical insufficiency is a potentially serious

Received on 14 November 2000; revised 10 April 2001.

Address for correspondence: Dr. Tania W. Furlanetto, M.D., Ph.D. Division of Internal Medicine. Hospital de Clínicas de Porto Alegre - Universidade Federal do Rio Grande do Sul. Rua Ramiro Barcellos 2350/700 Zip Code: 90035-003 Porto Alegre, RS, Brazil. Phone: 0(xx)(51) 22685 42. Fax: O(xx)(51) 3331585 .

The Brazilian Journal of Infectious Diseases 2001;5(2):53-59 (c) 2001 by The Brazilian Journal of Infectious Diseases and Contexto Publishing. All rights reserved.

$1413-8670$ complication of AIDS [2]. The adrenal gland is the endocrine gland most commonly affected in AIDS, by both opportunistic infections and Kaposi's sarcoma [3, 4], as shown in autopsy studies that revealed adrenocortical and medullar infection, and necrosis, primarily caused by cytomegalovirus, but also by Mycobacterium tuberculosis, Cryptoccocus neoformans, Toxoplasma gondii and M. avium intracellulare [5]. Neoplasm involvement is rare. In addition, drugs such as glucocorticoids and ketoconazole may cause pituitary-adrenal dysfunction by suppressing the hypothalamo-pituitary-adrenal axis (HPA) or by blocking adrenal steroid biosynthesis. Other drugs, such as rifampin and phenytoin, enhance glucocorticoid metabolic clearance that may lead to adrenal insufficiency in patients with a diminished adrenal reserve [6].

The estimated prevalence of adrenal insufficiency in AIDS patients is very high [7] in comparison to the general population [8]. However, reports of clinically significant adrenal insufficiency are rare. Patients with AIDS commonly manifest fatigue, anorexia, nausea and 
vomiting, orthostatic hypotension, and hyponatremia - nonspecific signs and symptoms that mimic those of adrenocortical insufficiency - that add to the diagnostic difficulty.

The integrity of the HPA axis in AIDS patients has been studied by measuring basal cortisol levels and cortisol response to $250 \mu \mathrm{g}$ of ACTH $[9,10]$. Recently, however, it has been shown that a maximal cortisol response can be elicited with a much lower ACTH dose than the $250 \mu \mathrm{g}$ dose commonly used. Also, there is a suggestion that a lower ACTH dose may further enhance the sensitivity of the procedure, especially in patients with a recent abnormality of the HPA axis [1116]. The standard $250 \mu \mathrm{g}$ ACTH stimulation test is probably reliable to indicate the need for steroid therapy when the result is abnormal. However, it is incorrect to assume that all patients whose serum cortisol levels rise following a $250 \mu \mathrm{g}$ ACTH injection are necessarily able to increase their serum cortisol enough to avoid the manifestations of adrenal insufficiency following severe stress caused by surgical procedures, infections, neoplasms, or other reasons [17].

The purpose of this work was to study the prevalence of adrenal hypofunction in AIDS patients using a low-dose ACTH test $(1 \mu \mathrm{g})$, to evaluate the clinical characteristics that can suggest this diagnosis, and to identify diseases and/or drugs that can be associated with it.

\section{Materials and Methods}

\section{$\underline{\text { Subjects }}$}

Between July, 1996, and March, 1998, 272 patients with a presumptive diagnosis of AIDS admitted to the Hospital de Clínicas de Porto Alegre for treatment, were evaluated for entry to the study. Of those evaluated, 182 patients were excluded: the diagnosis of AIDS was not confirmed in 60 patients, 98 were using glucorticoids or had used them during the month prior to the study, 7 were either unable to sign the informed consent form or to answer the questionnaire, 13 had no venous line access, and 4 died or were discharged before the ACTH test. Ninety patients were eligible for the study; 18 patients refused to participate. Therefore, 72 patients entered the study group.

The control group consisted of 16 normal volunteers with no history of adrenal disease, and who had not used glucocorticoids or hormonal contraceptives in the month preceding the test. The protocol was approved by the Ethics Committee of the hospital, and all participants gave written informed consent.

\section{$\underline{\text { Study Protocol }}$}

A standard questionnaire and clinical examination were used to assess age and signs or symptoms that could be related to adrenal insufficiency (presence of weakness, fatigue, weight loss, anorexia, nausea, vomiting, diarrhea, muscle or joint pain, arterial hypotension, hyperpigmentation, electrolyte abnormalities or a history of glucocorticoid use). After that, a low-dose ACTH test was performed for all participants. A $250 \mu \mathrm{g}$ vial of 1-24 ACTH (Cortrosyn ${ }^{\circledR}$, Organon International Oss) was diluted in sterile saline solution to a concentration of $1 \mu \mathrm{g} / \mathrm{mL}$. The solution was used immediately. An indwelling intravenous catheter was inserted into the forearm between 7:00 a.m. and 8:00 a.m. Blood samples was taken right before, and 30 and 40 minutes following the injection of $1 \mathrm{mg}$ of 1-24 ACTH. The serum samples were immediately separated and kept frozen at $-20^{\circ} \mathrm{C}$ until assayed. Cortisol was measured by radioimmunoassay (Coata-Count, DPC; normal range in the morning: $5 \mu \mathrm{g} /$ $\mathrm{dL}$ to $25 \mu \mathrm{g} / \mathrm{dL})$. Intraassay variability was $4.3 \%$; interassay variability was $5.2 \%$.

\section{$\underline{\text { Statistics }}$}

Results were compared using non parametric analysis of variance or the Mann-Whitney test, when indicated. Sensitivity, specificity, positive predictive value and negative predictive value for diagnostic tests were calculated by the theory of probabilities using the Epi-Info v. 6 program. All P values were two-sided; a $P$ value of less than 0.05 was considered to indicate statistical significance. 


\section{Results}

$\underline{\text { Patients }}$

During the 2-year study period, 72 critically ill AIDS patients were tested (diagnostic category C, Centers for Disease Control and Prevention). We were not able to obtain all 3 samples for 9 patients. The epidemiological data for these patients were similar to those of our general population of HIV infected patients. Among the 63 patients from whom samples were collected, most were young males (mean age: 34.5 years) and had a known risk factor for HIV infection: 16 (25.4\%) were intravenous drug users and $36(57.1 \%)$ had sexual intercourse with infected partners. The data for the study and control groups are described in Table 1.

\section{$\underline{\text { Low- ACTH test in healthy controls }}$}

Mean serum cortisol concentration observed in healthy controls before stimulation with $1 \mu \mathrm{g}$ of ACTH was $17.7 \mu \mathrm{g} / \mathrm{dL} \pm 7.3 \mu \mathrm{g} / \mathrm{dL}$. After 30 min, mean cortisol level was $26.2 \mu \mathrm{g} / \mathrm{dL} \pm 5.8 \mu \mathrm{g} / \mathrm{dL}$, and after $40 \mathrm{~min}$, mean serum cortisol level was $25.9 \mu \mathrm{g} / \mathrm{dL} \pm$ $6.6 \mu \mathrm{g} / \mathrm{dL}$. Each curve was evaluated individually; the lowest stimulated cortisol level in this group was 18.5 $\mu \mathrm{g} / \mathrm{dL}$, so we considered the HPA axis as normal when the patient had a serum cortisol level $\geq 18 \mathrm{mg} / \mathrm{dL}$ in at least 1 measurement.

Low- ACTH test in AIDS patients with normal response

A cortisol level $\geq 18 \mu \mathrm{g} / \mathrm{dL}$ was observed in 51 patients. Mean basal cortisol level was $19.1 \pm 7.0 \mu \mathrm{g} /$ $\mathrm{dL} ; 30$ min after ACTH application, mean cortisol level was $25.8 \pm 7.3 \mu \mathrm{g} / \mathrm{dL}$, and $40 \mathrm{~min}$ after ACTH, mean cortisol level was $24.2 \pm 7.0 \mu \mathrm{g} / \mathrm{dL}$.

$\underline{\text { Low-ACTH testin AIDS patients with abnormal response }}$

Cortisol levels below $18 \mu \mathrm{g} / \mathrm{dL}$ were observed in 12 patients. Mean basal cortisol level was $10.9 \pm 3.2$ $\mu \mathrm{g} / \mathrm{dL}$. Thirty min after the ACTH injection, mean cortisol level reached $13.5 \pm 3.0 \mu \mathrm{g} / \mathrm{dL}$; and $40 \mathrm{~min}$ after ACTH, mean cortisol level reached 14.3 \pm 1.5 $\mu \mathrm{g} / \mathrm{dL}$. Basal and stimulated cortisol levels were significantly lower than the ones detected in the control group and in the AIDS patients with normal response (there was no difference between these 2 last groups). These results are shown in Figure 1.

Basal cortisol levels were less than $14.2 \mu \mathrm{g} / \mathrm{dL}$ in all AIDS patients in this group (19\% of our AIDS patients). Using $14.5 \mu \mathrm{g} / \mathrm{dL}$ as a cut-off point, sensitivity of basal cortisol levels to detect adrenal hypofunction was $100 \%$; specificity was $73 \%$, positive predictive value was $46 \%$ and negative predictive value was $100 \%$. In Figure 2, the relation of sensitivity and specificity to detect adrenal insufficiency using different basal cortisol levels as cutoff points is shown (ROC curve).

As shown in Table 2, all of our AIDS patients had been diagnosed with at least 1 AIDS-related disease [18]: tuberculosis in $31.3 \%$ of the patients, Pneumocystis carinii pneumonia in $20.3 \%$, cytomegalovirus in $7.8 \%$, central nervous system toxoplasmosis in $6.3 \%$, and histoplasmosis in $6.3 \%$. There was no association between presence of abnormal adrenal function and any of these diseases.

Signs or symptoms suggestive of adrenal insufficiency were observed frequently but, as shown in Table 3, there was no difference in the prevalence of these clinical features in AIDS patients with normal or abnormal cortisol response to ACTH. Use of drugs that could affect adrenal function, such as ketoconazole, rifampin, phenytoin, opioids and anticoagulants, was not more frequent in AIDS patients with abnormal cortisol response when compared to AIDS patients with normal cortisol response, as shown in Table 4.

\section{Dicussion}

The current study prospectively examined adrenal response to a low dose ACTH test $(1 \mu \mathrm{g})$ in 63 AIDS patients (category $\mathrm{C}$, Center for Disease Control and Prevention) and evaluated clinical characteristics that might suggest a diagnosis of adrenal hypofunction, as well as diseases and drugs that could be associated with its presence. 
Table 1. Clinical characteristics of patients and controls

\begin{tabular}{lcccc}
\hline Group & $\mathbf{n}$ & Mean age (range) in years & \% males & \% Caucasian \\
\hline Control & 16 & $31.6(22-49)$ & 62.5 & 100 \\
AIDS (all) & 63 & $34.6(16-62)$ & 79.2 & 73 \\
AIDS-N* & 51 & $34.9(16-62)$ & 76.5 & 74 \\
AIDS-Ab** & 12 & $32.8(26-43)$ & 91.7 & 70 \\
\hline
\end{tabular}

*AIDS patients with at least 1 cortisol measurement $\geq 18 \mu \mathrm{g} / \mathrm{dL} ; * *$ AIDS patients with all cortisol measurements $<18 \mu \mathrm{g} / \mathrm{dL}$.

Table 2. Prevalence of AIDS diagnostic criteria in the studied population ${ }^{\mathrm{a}}$

\begin{tabular}{lcccc}
\hline Criterion & $\begin{array}{c}\text { AIDS-N* } \\
(\mathbf{n = 5 1 )}\end{array}$ & $\%$ & $\begin{array}{c}\text { AIDS-Ab** } \\
(\mathbf{n = 1 2})\end{array}$ & $\%$ \\
\hline Cytomegalovirosis & 5 & 8.3 & 1 & 8.3 \\
Toxoplasmosis & 5 & 8.3 & 0 & - \\
Tuberculosis & 19 & 31.7 & 6 & 50.0 \\
CD $_{4}<200$ cells/ $\mu \mathrm{L}$ & 1 & 1.7 & 2 & 16.7 \\
Histoplasmosis & 4 & 6.7 & 2 & 16.7 \\
Cryptococcosis & 4 & 6.7 & 1 & 8.3 \\
Candidainfection & 5 & 8.3 & 1 & 8.3 \\
Kaposi's sarcoma & 3 & 5.0 & 1 & 8.3 \\
P. carinii pneumonia & 11 & 18.3 & 3 & 25.0 \\
Diarrhea >3 month & 9 & 15.0 & 3 & 25.0 \\
Herpes Zoster infection & 2 & 3.3 & 0 & - \\
\hline
\end{tabular}

${ }^{a}$ Centers for Disease Control criteria. *AIDS patients with at least 1 cortisol measurement $\geq 18 \mu \mathrm{g} / \mathrm{dL}$; **AIDS patients with all cortisol measurements $<18 \mu \mathrm{g} / \mathrm{dL}$.

Table 3. Clinical data of AIDS patients

\begin{tabular}{lcccc}
\hline Symptom/sign & $\begin{array}{c}\text { AIDS-N* } \\
(\mathbf{n}=\mathbf{5 1})\end{array}$ & \% & $\begin{array}{c}\text { AIDS-Ab ** } \\
(\mathbf{n = 1 2})\end{array}$ & \% \\
\hline Fatigue & 27 & 55.1 & 9 & 75.0 \\
Weakness & 26 & 53.1 & 5 & 41.7 \\
Anorexia & 24 & 49.0 & 5 & 41.7 \\
Nausea & 20 & 40.8 & 6 & 50.0 \\
Vomiting & 16 & 32.7 & 5 & 41.7 \\
Diarrhea & 16 & 32.7 & 3 & 25.0 \\
Weight loss & 36 & 73.5 & 10 & 83.3 \\
Muscle pain & 11 & 22.4 & 6 & 50.0 \\
Joint pain & 12 & 49.0 & 3 & 25.0 \\
Serum Na ${ }^{+}$(mean \pm SD) & $133.2 \pm 5.0$ & - & $133.6 \pm 2.5$ & \\
Serum $\mathrm{K}^{+}$(mean \pm SD) & $4.2 \pm 0.6$ & & $3.7 \pm 0.8$ & \\
*AIDS patients with at least 1 cortisol measurement $\geq 18 \mu \mathrm{g} / \mathrm{dL} ; * *$ AIDS patients with all cortisol measurements \\
$<18 \mu \mathrm{g} / \mathrm{dL}$.
\end{tabular}


Table 4. Used drugs potentially affecting adrenal function

\begin{tabular}{lcccc}
\hline Drugs & $\begin{array}{c}\text { AIDS-N* } \\
(\mathbf{n = 5 1 )}\end{array}$ & $\mathbf{\%}$ & $\begin{array}{c}\text { AIDS-Ab** } \\
(\mathbf{n = 1 2})\end{array}$ & $\mathbf{\%}$ \\
\hline Ketoconazole & 8 & 16 & 2 & 16.6 \\
Opioids & 8 & 16 & 1 & 8.3 \\
Rifampin & 5 & 10 & 1 & 8.3 \\
Phenytoin & 2 & 4 & - & - \\
Anticoagulants & 9 & 18 & - & - \\
\hline
\end{tabular}

*AIDS patients with at least 1 cortisol measurement $\geq 18 \mu \mathrm{g} / \mathrm{dL} ; * *$ AIDS patients with all cortisol measurements $<18 \mu \mathrm{g} / \mathrm{dL}$.

Figure 1. Serum cortisol levels before and after $1 \mu \mathrm{g}$ ACTH. Results are shown as median and $75^{\text {th }}$ and $25^{\text {th }}$ percentiles. AIDS-N: AIDS patients with normal cortisol response. AIDS-Ab: AIDS patients with abnormal cortisol response. $\delta$ : $\mathrm{p}<0.01$ versus control; $\varepsilon$ : $\mathrm{p}<0.00004$ versus AIDS-N; $\phi$ : $\mathrm{p}<0.00002$ versus control; $\gamma: \mathrm{p}<$ 0.000000 versus AIDS-N; $\varphi$ : $p<0.000008$ versus control; $\kappa: p<0.000001$ versus AIDS-N.

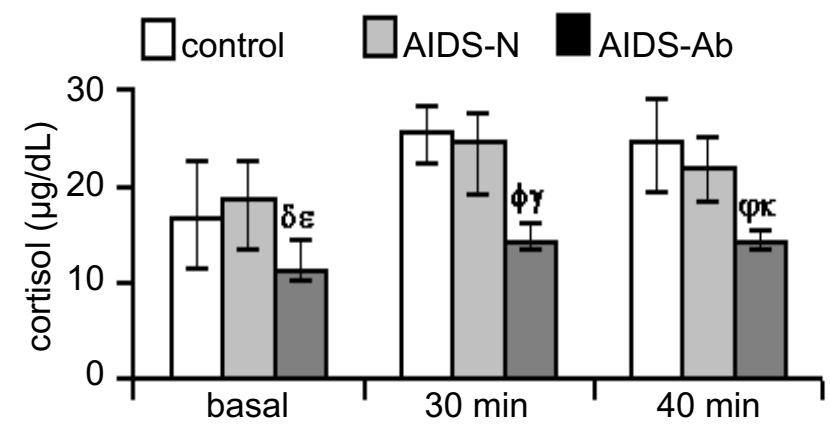

Figure 2. ROC curve showing the relation of sensitivity and specificity of the basal cortisol level to detect adrenocortical dysfunction

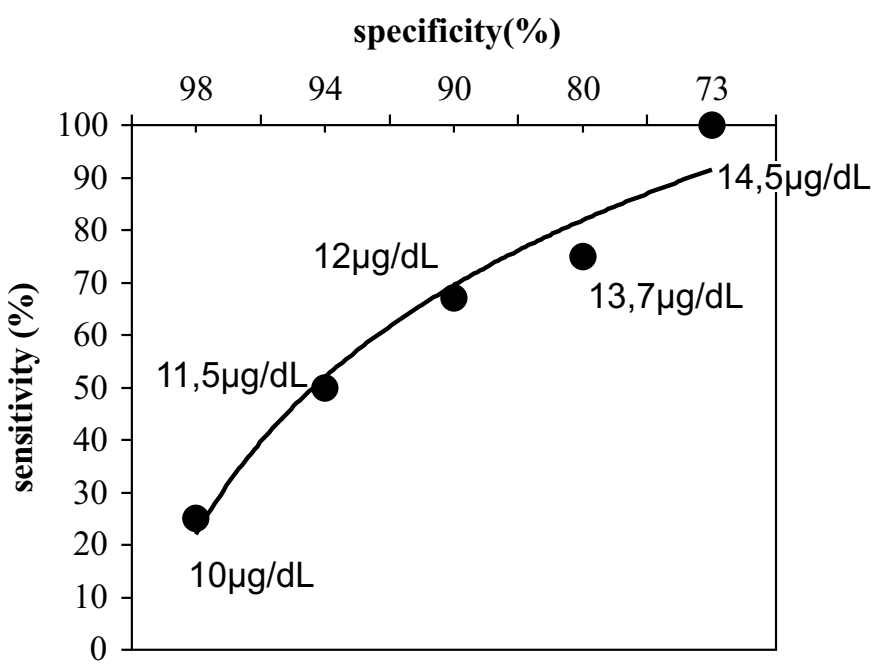


Our data show that $19 \%$ of our stage C AIDS patients had an abnormal response to $1 \mu \mathrm{g} \mathrm{ACTH}$, considering a cortisol level $\geq 18 \mu \mathrm{g} / \mathrm{dL}$ as normal. This cut-off point was established by the study of a control group and is very similar to those established in other studies $[9,19]$. The prevalence of adrenal hypofunction is larger than reported or estimated previously, using the $250 \mu \mathrm{g} \mathrm{ACTH}$ test, the reported prevalence ranged from $0 \%$ to $8 \%[7$, 14, 20-23]. This have been the result of different intervening factors, like the exclusion of 90 patients using glucocorticoids with an unknown, but potentially normal, adrenal function; or the fact that our patients were very ill, and therefore had more infections and less immunity than other AIDS patients. Nevertheless, it may be that the low dose ACTH test $(1 \mu \mathrm{g})$ is, indeed, more sensitive for the diagnosis of adrenal hypofunction.

There have been reports of increased basal cortisol levels in AIDS patients [21, 24]. In our study, AIDS patients with normal response to ACTH did not have increased basal cortisol levels. Using a cut-off point of $14.5 \mathrm{mg} / \mathrm{dL}$ for basal cortisol, all adrenal insufficient patients were identified, but the positive predictive value was $46 \%$.

Frank adrenal dysfunction has rarely been reported in HIV infected patients, although the adrenal gland is frequently affected by opportunistic infections or Kaposi's sarcoma [25,26]. Usually, clinically apparent adrenal dysfunction appears only after more than $90 \%$ of the adrenal glands have been destroyed, but a diagnosis of adrenal insufficiency should be considered in certain clinical situations [8].

Symptoms of adrenal insufficiency are very difficult to assess in AIDS patients with advanced disease, since symptoms can be present even when adrenal function is normal [27]. These symptoms were commonly seen in our patients, but they were nonspecific and there was no clinical feature associated to adrenal hypofunction.

Present use of drugs that could interfere with the adrenal function or past use of glucocorticoids (discontinued for more than 30 days) were not predictive of an abnormal response to ACTH. The prevalence of diseases that could affect the adrenal gland was the same in our patients with normal or abnormal responses to ACTH. Similar findings concerning tuberculosis were described recently [28]. Our data suggest that an abnormal response to $1 \mu \mathrm{g}$ ACTH is very common in late stage AIDS patients, and that there are no clinical findings and no diseases or drugs that can signal the presence of adrenal hypofunction. The group of AIDS patients that we studied was severely ill. Except for 1 patient, all of the patients were treated with a combination of drugs, and a large percentage of them showed weight loss, fatigue, and weakness - three cardinal manifestations of adrenocortical failure. With these data in mind, we suggest a prospective evaluation of the adrenal function, using a method such as the low dose ACTH test, in all AIDS patients when they are in an advanced stage of the disease.

\section{Acknowledgement}

Fundação de Amparo à Pesquisa do Rio Grande do Sul (FAPERGS).

\section{References}

1. Dluhy R. The growing spectrum of HIV-related endocrine abnormalities. J Clin Endocrinol Metab 1990;70:563-4.

2. Aron D.C. Endocrine complications of the acquired immunodeficiency syndrome. Arch Intern Med 1989; 149:330-3.

3. Reichert C.M., O’Leary T.J., Levens D.L., et al. Autopsy pathology in the acquired immune deficiency syndrome. Am J Pathol 1983; 112:357-82.

4. Glasgow B.J., Steinsapir K.D., Anders K., et al. Adrenal pathology in the acquired immune deficiency syndrome. Am J Clin Pathol 1985;84:594-7.

5. Bricaire F., Marche C., Zoubi D., et al. Adrenocortical lesions and AIDS [letter]. Lancet 1988;1:881.

6. Freda P.U., Wardlaw S.L., Brudney K., Goland R.S. Clinical case seminar: Primary adrenal insufficiency in patients with the acquired immunodeficiency syndrome: A report of five cases. J Clin Endocrinol Metab 1994;79:1540-5.

7. Raffi F., Brisseau J.M., Planchon B., et al. Endocrine function in $98 \mathrm{HIV}$ infected patients: a prospective study. AIDS 1991;5:729-33.

8. Werbel S.S., Ober K.P. Acute adrenal insufficiency. Endocrinol Metab Clin North Am 1993;22:303-28.

9. Piedrola G., Casado J.L., López E., et al. Clinical features of adrenal insufficiency in patients with acquired immunodeficiency syndrome. Clin Endocrinol 1996;45:97-101. 
10. Stolarczyk R., Rubio S.I., Smolyar D., et al. Twentyfour-hour urinary free cortisol in patients with the acquired immunodeficiency syndrome. Metabolism 1998;47:690-4.

11. Tordjman K., Jaffe A., Grazas N., et al. The role of the low dose $(1 \mathrm{mg})$ adrenocorticotropin test in the evaluation of patients with pituitary diseases. J Clin Endocrinol Metab 1995; 80:1301-5.

12. Dickstein G., Schechner C., Nicholson W.E., et al. Adrenocorticotropin stimulation test: effects of basal cortisol level, time of the day, and suggested new sensitive low dose test. J Clin Endocrinol Metab 1991;72:773-8.

13. Crowley S., Hindmarsh P.C., Honour J.W., Brook C.G.D. Reproducibility of the cortisol response to stimulation with a low dose of ACTH(1-24): the effect of basal cortisol levels and comparison of low dose with high dose secretory dynamics. J Endocrinol 1993;136:167-72.

14. Baraia-Etxaburu Artetxe J., Astigarraga Aguirre B., Elorza Olabegova R., et al. [Primary adrenal failure and AIDS: report of 11 cases and review of the literature]. Rev Clin Esp 1998; 198:74-9.

15. Zarkovic M., Ciric J., Stojanovic M., et al. Optimizing the diagnostic criteria for standard (250-mg) and low dose (1-mg) adrenocorticotropin tests in the assessment of adrenal function. J Clin Endocrinol Metab 1999;84:3170-3.

16. Abdu T.A., Elhadd T.A., Neary R., Clayton R.N. Comparison of the low dose short synacthen test (1 $\mathrm{mg}$ ), the conventional dose short synacthen test (250 $\mathrm{mg}$ ), and the insulin tolerance test for assessment of the hypothalamo-pituitary-adrenal axis in patients with pituitary disease. J Clin Endocrinol Metab 1999; $84: 838-43$.

17. Streeten D.H., Anderson G.H., Bonaventura M. The potential for serious consequences from misinterpreting normal responses to the rapid adrenocorticotropin test. J Clin Endocrinol Metab 1996;81:285-90.

18. Grinspoon S.K., Bilezikian J.P. HIV disease and the endocrine system. N Engl J Med 1992;327:1360-5.

19. Weintrob N., Sprecher E., Josefsberg Z., et al. Standard and low dose short adrenocorticotropin test compared with insulin induced hypoglycemia for assessment of the hypothalamo-pituitary-adrenal axis in children with idiopathic multiple pituitary hormone deficiencies. J Clin Endocrinol Metab 1998;83:88-92.

20. Peter A.S., Bruschetta H., Vergara R. Glucocorticoid reserve in patients with acquired immunodeficiency syndrome. Horm Res 1995;44:85-88.

21. Lortholary O., Christeff N., Casassus P., et al. Hypothalamopituitary-adrenal function in human immunodeficiency virus-infected men. J Clin Endocrinol Metab 1996; $81: 791-6$
22. Verges B., Chavanet P., Desgres J., et al. Adrenal function in HIV infected patients. Acta Endocrinol (Copenh). 1989;121:633-7.

23. Hilton C.W., Harrington P.T., Prasad C., Svec F. Adrenal insufficiency in the acquired immunodeficiency syndrome. South Med J 1988;81:1493-5.

24. Membreno L., Irony I., Dere W., Klein R., et al.. Adrenocortical function in acquired immunodeficiency syndrome. J Clin Endocrinol Metab 1987;65:482-7.

25. Pulakhandam U., Dincsoy H.P. Cytomegaloviral adrenalitis and adrenal insufficiency in AIDS. Am J Clin Pathol 1990;93:651-6.

26. Guarda L.A., Luna M.A., Smith J.L. Jr, et al. Acquired immune deficiency syndrome: postmortem findings. Am J Clin Pathol 1991;81:549-57.

27. Dore M.X., de La Blanchardiere A., Lesprit P., et al. Peripheral adrenal insufficiency in AIDS. Rev Med Interne 1998; 19 :23-8.

28. Hawken M.P., Ojoo J.C., Morris J.S., et al. No increased prevalence of adrenocortical insufficiency in human immunodeficiency virus-associated tuberculosis. Tuber Lung Dis 1996; 77:444-8. 